\title{
A PARTICIPAÇÃO DO NÍVEL OPERACIONAL NO PROCESSO DE FORMULAÇÃO DE ESTRATÉGIAS
}

\section{OPERATIONAL LEVEL PARTICIPATION IN THE DEVELOPMENT PROCESS OF STRATEGIES}

\section{LA PARTICIPACIÓN DEL NIVEL OPERACIONAL EN EL PROCESO DE FORMULACIÓN DE LAS ESTRATEGIAS}

\section{Aslei Andrade da Silva}

Mestre em Administração pelo Centro Universitário Euro-Americano - UNIEURO

Coordenador do Curso de Administração da Faculdade Apogeu

E-mail: aslei.andrade@gmail.com (Brasil)

\section{Sérgio Luiz Lepsch}

Doutor em Administração de Empresas pela Universidade de São Paulo - USP

Professor do Programa de Mestrado do Centro Universitário Euro-Americano - UNIEURO

E-mail: slepsch@gmail.com (Brasil) 


\section{A PARTICIPAÇÃO DO NÍVEL OPERACIONAL NO PROCESSO DE FORMULAÇÃO DE ESTRATÉGIAS}

\section{RESUMO}

Este artigo teve como principal objetivo investigar, por meio de um estudo multicaso junto a cinco organizações no Distrito Federal, a participação do nível operacional na etapa de formulação do processo estratégico e sua integração com os demais níveis hierárquicos dessas empresas. Adotando-se como referencial teórico a concepção de estratégia e do processo estratégico como uma realidade construída de forma interativa e contextual, optou-se por uma pesquisa exploratória qualitativa para atingir-se o propósito da investigação e pela análise de conteúdos discursivos para analisar as informações obtidas. Os resultados dessa pesquisa revelam que apesar dos níveis hierárquicos mais elevados (estratégico e tático) considerarem muito importante a participação dos colaboradores do nível operacional na formulação do processo estratégico, o que se observa na prática é que essa se dá de maneira tímida. A alta direção das empresas envolve esses funcionários em alguns momentos do processo e os abstém de outros e esta ruptura pode comprometer todo o ciclo do processo estratégico e, em consequência, os resultados esperados no longo prazo. Relativo à distribuição de poder com o objetivo de tornar a participação ativa, em todas as entidades de classe pesquisadas, a estrutura fortemente politizada e tradicional não permite tal atividade. $\mathrm{O}$ principal achado do trabalho é mostrar que a importância do operacional no processo estratégico, não é suficiente para convencer as organizações excessivamente hierarquizadas sobre sua real participação.

Palavras-chave: Estratégia em Organizações; Processo Estratégico; Formulação Integrativa do Processo Estratégico.

\section{OPERATIONAL LEVEL PARTICIPATION IN THE DEVELOPMENT PROCESS OF STRATEGIES}

\section{ABSTRACT}

The prime objective of this article is to investigate, through a multi-case study of five organizations from Brazil's Federal District, the operational level participation in the formulation phase of the strategic process and integration of these professionals with other hierarchical levels in organizations. Based on the theoretical referential that the conception of strategy and the strategic process is a reality built in an interactive and contextual manner, we opted for an exploratory qualitative research to investigate and analyze the data collected from the statements of interviewees. The results of this research reveal that although higher hierarchical levels (strategic and tactic) regard the participation of operational level professionals as vitally important to formulate the strategic process, in effect, that occurs in a limited fashion. Top management in 
organizations involves these professionals at various stages of the process, and neglects them in others. This omission can compromise the entire cycle of the strategic process and, consequently, the results to be obtained from it. In all studied organizations, there was no power distribution to allow for active participation - the highly political and traditional structure does not permit said activity. The primary finding of this study is to demonstrate that the importance of the operational level in the strategic process is not sufficient to drive excessively hierarchical organizations to grant them true participation.

Keywords: Organizational Strategy; Strategic Process; Participative Formulation of the Strategic Process.

\section{LA PARTICIPACIÓN DEL NIVEL OPERACIONAL EN EL PROCESO DE FORMULACIÓN DE LAS ESTRATEGIAS}

\section{RESUMEN}

Este artículo tuvo como principal objetivo investigar, por medio de un estudio multicaso en cinco organizaciones del Distrito Federal, la participación del nivel operacional en la etapa de la formulación del proceso estratégico y su integración con los demás niveles jerárquicos de esas empresas. Como referencial teórico se adoptó la concepción de la estrategia y del proceso estratégico como una realidad construida de forma interactiva y contextual, para alcanzar el propósito de la investigación se optó por una investigación exploratoria cualitativa y por el análisis de contenidos discursivos para analizar las informaciones obtenidas. Los resultados de esta investigación revelan que a pesar de que los niveles jerárquicos más elevados (estratégico y táctico) consideran muy importante la participación de los colaboradores del nivel operacional en la formulación del proceso estratégico, lo que se observa en la práctica es que eso ocurre de manera tímida. La alta dirección de las empresas involucra a esos funcionarios en algunos momentos del proceso y los abstienen de otros y esta ruptura puede comprometer todo el ciclo del proceso estratégico $\mathrm{y}$, en consecuencia, los resultados esperados a largo plazo. En lo relativo a la distribución de poder, con el objetivo de hacer la participación activa, en todas las entidades de clase investigadas, la estructura fuertemente politizada y tradicional no permite tal actividad. El principal resultado del trabajo es mostrar que la importancia del nivel operacional en el proceso estratégico, no es suficiente para convencer a las organizaciones, excesivamente jerarquizadas, sobre su real participación.

Palabras-clave: Estrategia en las Organizaciones; Proceso Estratégico; Formulación Integradora del Proceso Estratégico. 
A Participação do Nível Operacional no Processo de Formulação de Estratégias.

\section{INTRODUÇÃO}

Estratégias são ações relevantes para a organização cumprir ou atingir, no seu processo de gestão de longo prazo, determinado objetivo. Costumam nascer em ambientes onde haja pessoas capacitadas e interessadas em aprender cada vez mais e se aperfeiçoam para conservar essa capacidade. Os estudos sobre estratégia são sempre relevantes para o entendimento da gestão empresarial, podendo ser visualizados sobre vários enfoques, em especial aos estudos sobre a formulação do processo estratégico.

Mintzberg e Quinn (2001) comentam que o processo estratégico (formulação, ajustes e implementação) necessita de mudança na responsabilidade de quem o cria. Isso porque os problemas na implementação podem aumentar devido à mudança nesse fator, especialmente se as decisões estratégicas chegam de surpresas aos níveis hierárquicos inferiores e os encontram despreparados. A democracia do processo estratégico cunhada por estes autores afirma que a participação de todos os níveis organizacionais, ainda que por representação, possui elementos positivos. Essa abordagem observa, também, a distribuição de poder em uma organização como elemento complementar às ações participativas.

A visão sob a perspectiva da participação do nível operacional no processo de formulação das estratégias organizacionais ainda é pouco estudada pela academia. Todavia, na prática, há um crescente reconhecimento em importantes organizações de que os diferentes níveis hierárquicos, em especial o operacional, têm valiosas contribuições sobre os caminhos a serem seguidos para sua expansão. Essas mudanças referem-se, principalmente, às novas exigências do mercado-alvo (lado da demanda); à redução dos custos e introdução de novos produtos (lado da oferta); sobre as ações da concorrência; tecnologia; inovação e outras questões que ajudarão a moldar a estratégia. $\mathrm{O}$ desafio consiste em estabelecer processos que permitam ampla participação sob uma forma aplicável na prática, aproveitando ideias e gerando energia positiva para as mudanças. Importantes autores como Almeida (2000), Ouchi (2000) e Mintzberg (2003) citam que o processo estratégico pode se iniciar de forma espontânea com o desenvolvimento cultural e da distribuição do poder ou com o apoio de consultores, de maneira mais formal, expondo e debatendo as questões estratégicas junto a todos os colaboradores da empresa. Já Costa, Boaventura e Barreto (2010) lembram que um dos aspectos de maior relevância no processo estratégico é a dificuldade em formular estratégias por questões de participação e mobilização de envolvidos.

Revista Ibero-Americana de Estratégia RIAE, São Paulo, v. 10, n. 1, p. 170-194, jan/abr. 2011. 


\subsection{PROBLEMA DE PESQUISA}

O presente artigo versa sobre a participação do nível operacional na etapa de formulação do processo estratégico. Problematiza-se a pesquisa através das seguintes questões: a) Que procedimentos são utilizados pelas organizações para envolver os colaboradores de nível operacional na formulação de estratégias? ; b) Existe percepção por parte dos diferentes níveis hierárquicos de que o nível operacional deve ter participação ativa durante o processo de formulação de estratégias? ; c) Qual a visão, entre os diferentes níveis hierárquicos, a respeito da distribuição do poder para efetivar a integração de todos na formulação de estratégias?

\subsection{OBJETIVOS}

O objetivo principal deste trabalho é investigar os procedimentos existentes em cinco organizações selecionadas no Distrito Federal a respeito do estímulo e da valorização da participação de funcionários de nível operacional na etapa de formulação de estratégias. Além disso, pretende-se esclarecer como os colaboradores que atuam nos níveis estratégico, tático e operacional percebem a existência ou não de distribuição de poder durante a formulação de estratégias para tornar a participação ativa. Como objetivo secundário, pretende-se verificar a possibilidade de estender ou realizar novas pesquisas acadêmicas sobre a participação do nível operacional na etapa de formulação de estratégias com foco em gestão.

Para a consecução dos objetivos deste artigo, além desta introdução, serão apresentadas a revisão de literatura, a metodologia, a análise dos resultados, a conclusão e, por fim, contribuições, extensões e limitações do estudo.

\section{REVISÃO DE LITERATURA}

\subsection{CONCEITOS DE ESTRATÉGIA, PODER E NÍVEIS HIERÁRQUICOS.}

Ao definir estratégias, a literatura busca relacionar a ferramenta à consecução de processos complexos inerentes aos desejos e às visões organizacionais. Lepsch (2001) traz um compêndio de fatores que norteiam as diferentes visões de estratégia e, dentre elas, destaca a busca de padrões unificadores e a necessidade de engajamento de variados níveis hierárquicos. Andrews (apud 
A Participação do Nível Operacional no Processo de Formulação de Estratégias.

MINTZBERG e QUINN, 2001) define a estratégia corporativa como o padrão de decisões da empresa, onde estão determinados os objetivos e metas, as políticas e planos para obtenção dos objetivos. O modelo de definição do autor também define a escala do negócio e da atuação organizacional, congrega decisões estratégicas que se mostram eficazes ao longo do tempo e tende a definir o caráter, a imagem e posição que a organização ocupará no mercado. Belo (2010) lembra que a realização do desenvolvimento passa por estratégias objetivas que prevejam como se fazer e o quê se fará para torná-lo real.

O poder é visto, de maneira genérica, como processo de convencimento e influência por meio de elementos sociais, políticos e hierárquicos no qual um indivíduo dotado de poder o exerce de maneira a auferir resultados por intermédio de outro ou outros (FERREIRA; VILAMAIOR; GOMES, 2005). Foucault (1992), um dos maiores pensadores do tema, entende que o uso do poder é elemento de mão dupla. Ou seja, ao se utilizar a prerrogativa de empoderamento, o indivíduo se submete às reações que efetivamente ocorrerão, já que se trata de construto de cunho essencialmente social e coletivo. Se este é difundido apenas no nível hierárquico mais elevado, ocorre redução de interação e criação de gargalo entre a formulação da estratégia e sua execução.

Conceitualmente apresentam-se à academia três níveis hierárquicos distintos entre si. $\mathrm{O}$ nível estratégico funciona como ponto de referência da empresa para tratar assuntos relativos aos aspectos ambientais internos e externos da organização. No nível tático encontram-se os atores responsáveis por intermediar ações estratégicas e operacionais. O nível operacional é o grupo responsável por desenvolver as ações de rotina e criar métodos de trabalho que viabilizem o alcance dos objetivos organizacionais. A literatura argumenta ser este nível o mais atuante no que tange a ações administrativas (OLIVEIRA, 2008).

\subsection{FORMULAÇÃO DE ESTRATÉGIAS NO PROCESSO ESTRATÉGICO E A PARTICIPAÇÃO DO OPERACIONAL}

Na visão de Mintzberg, Ahlstrand e Lampel (2000), a formulação da estratégia é sempre voltada para a excelência da ideia. Esses autores discutem os resultados de um experimento feito com 12 moscas e 12 abelhas presas em uma garrafa deitada horizontalmente e com a base voltada para a janela. As abelhas morrem tentando passar pelo fundo da garrafa por achar que a saída está na direção da luz. As moscas, em menos de dois minutos, encontram a liberdade após andar de um lado para o outro. A analogia entre a inteligência das esvoaçadas abelhas e das idiotas moscas é levantada para em seguida surgir a pergunta: "Será que temos abelhas demais fazendo estratégia e

Revista Ibero-Americana de Estratégia RIAE, São Paulo, v. 10, n. 1, p. 170-194, jan/abr. 2011. 
muito poucas moscas?’. Panegalli (2004) acrescenta que a justificativa comum, apresentada quando os resultados de uma estratégia não são atingidos, é a falha de formulação. Para esse autor, o processo de formulação estratégica é definido como utilização de informações geradas por análises estratégicas, operacionais, organizacionais e funcionais. Os pesquisadores Almeida, Machado, Raifur e Nogueira (2009) concluíram em estudo que conforme a participação de colaboradores aumenta, maior é a ocorrência positiva de utilização das ferramentas analisadas na formulação e implementação de estratégias.

O marco zero do processo estratégico é o momento em que se define o tipo de trabalho que será realizado. O conhecimento a respeito da ferramenta e seu alcance acompanham o início do processo já que os participantes devem dominar conceitos e relações organizacionais da estratégia (QUINN apud MINTZBERG e QUINN, 2001). No processo tem-se a formulação como início das ações diretas. Na visão de Andrews (apud MINTZBERG e QUINN, 2001) é uma atividade que tem como principal apoio a análise SWOT. Formular é o momento de grande importância no processo estratégico. É responsável pela assertividade de metas e objetivos e de destrinchar, em minúcia, o teor da estratégia traçada. Para tal atividade as organizações costumam aproveitar informações colhidas por intermédio de estudos de apoio como a já citada análise SWOT.

Em uma estrutura participativa, a forma de se ver a empresa é de dentro para fora e de fora para dentro. Os indivíduos não se atêm à simples tarefa de observar e esperar o resultado das forças. Com isso, ganha a organização como um todo, já que funcionários atentos produzem mais, oferecem mais ideias e se comprometem mais com os resultados planejados (LERNER, 1996). Para tal, são necessárias atitudes gerenciais para promover essa participação. Organizações têm em seu poder a chance de criar estruturas hierárquicas fechadas ou abertas, podendo, ainda, ser chamadas de centralizadas e descentralizadas. Para este artigo a compreensão melhor ajustada é a de distribuir ou descentralizar o poder em toda a empresa, de maneira a tornar os colaboradores mais participativos e produtivos (MINTZBERG, 2003).

Panegalli (2004) apresenta argumentos de pesquisadores e autores sobre o fato de objetivos empresariais trazerem relevante necessidade de compreensão, comunicação, mensuração e, em especial, de relacionamento entre todos os níveis da organização para alcançar maior efetividade. A existência de uma visão sistêmica organizacional por parte dos colaboradores começa com ações da empresa para que tal visão surja. Em organizações do setor de serviços, por exemplo, os colaboradores da base vão ser seu espelho perante seus clientes e, assim, a imagem apresentada deve ser de força e segurança. Esses cidadãos devem sentir, em sua atividade comum, a importância

Revista Ibero-Americana de Estratégia RIAE, São Paulo, v. 10, n. 1, p. 170-194, jan/abr. 2011. 
A Participação do Nível Operacional no Processo de Formulação de Estratégias.

estratégica que ela tem e retribuir a sensação em comprometimento, dinâmica e desempenho (SALLY HELGESEN apud HESSELBEIN; GOLDSMITH e BECKHARD, 1996).

\subsection{DiSTRIbUiÇÃo de PODER (VISÃo ORGANIZACIONAL) E A PARTICIPAÇÃo ATIVA}

Quando o poder é delegado a um grupo distinto, existe maior probabilidade de ocorrer interação e interseção de opiniões. Neste caso, as pessoas seguem mais facilmente um padrão estrutural se compuserem uma mesma classe de poder. Em estruturas modernas, a hierarquia funciona de maneira mais democrática. Deixa claro aos participantes que eles precisam, necessariamente, demonstrar a eficácia de seu potencial (CHARLES HANDY apud HESSELBEIN et al., 1996). Historicamente o poder tem estado nas mãos de indivíduos portadores do status de "braço direito" ou "homem de confiança" de um gestor ou de um grupo de gestores superiores. Whiteley (1992) apresenta os resultados de pesquisa realizada em grande empresa japonesa. Esta revela que, numa lista de grandes problemas, $4 \%$ são de conhecimento da alta administração, $9 \%$ da média administração, $74 \%$ da baixa administração e $100 \%$ são de conhecimento do operacional. No entanto, atitudes positivas que aproveitam esse conhecimento de $100 \%$ dos problemas demandam, também, ofertar poder a quem o possui. Um exemplo próximo do ideal seria a Toyota, segundo o autor.

As atividades que movem a máquina organizacional necessariamente passam em mãos humanas por intermédio de relações nos mais variados níveis. Segundo Dutra (apud FLEURY e FISCHER, 1996), para o correto direcionamento da cultura da empresa, faz-se necessária a compenetração de todos os níveis organizacionais. É necessário ter preocupação com as ferramentas para atingir esse rumo e, entre elas, se encontra a distribuição de poder. O perfil do profissional que trabalha aguardando o momento de ir embora não condiz com o moderno mundo dos negócios na visão de Maximiano (1995), Mintzberg, Ahlstrand e Lampel (2000), Pereira e Fonseca (1997), para citar alguns. Essa discussão existe com o objetivo de deixar claro aos estudiosos o fato de que o trabalho em grupo com o colaborador participando das principais decisões empresariais é essencial (PEREIRA e FONSECA, 1997). Ocorre que, para o indivíduo decidir algo em um ambiente organizacional, ele precisa possuir algum tipo de poder, caso contrário seriam ideias lançadas ao vento, sem controle ou feedback. Brunstein (2009) entende que o poder é balanceado no momento em que as ações deixam a ótica individual para a coletiva, isso em aspectos políticos e organizacionais.

Revista Ibero-Americana de Estratégia RIAE, São Paulo, v. 10, n. 1, p. 170-194, jan/abr. 2011. 


\section{MÉTODO}

Esta investigação se fez por meio de um estudo multicaso, de caráter exploratório, junto a cinco organizações classistas que atuam no Distrito Federal. As organizações se caracterizam em: atividade privada sem fins lucrativos (uma) e autárquica federal (quatro). Para a concretização da pesquisa, foram realizadas 13 entrevistas sendo seis com respondentes do nível estratégico, quatro de nível tático e três de nível operacional. Para preservar a identidade das organizações investigadas, foram omitidos os nomes das mesmas adotando-se os nomes "A", "B", "C", "D" e "E".

As entrevistas foram do tipo semi-estruturadas, visando a obtenção de maior liberdade de resposta e condução das mesmas (GIL, 1995). Antes, porém, realizou-se um pré-teste com o objetivo de verificar a validade e a confiabilidade das questões propostas aos respondentes (RICHARDSON et cols., 2008). Os entrevistados receberam breve comentário sobre o estudo, seu objetivo e sua sistemática. As entrevistas foram gravadas em voz e transcritas para análise posterior.

Como eixo metodológico principal da análise dos dados coletados, optou-se pela adoção da análise de conteúdo, definida como "um conjunto de instrumentos metodológicos em constante aperfeiçoamento, que se aplicam a 'discursos' (conteúdos e continentes) extremamente diversificados" (BARDIN, 1977, pg. 9). Tal análise foi realizada estruturando as palavras no contexto em foco, para interpretar significados (VERGARA, 2008). Ademais, o sistema funcional com a figura do presidente e de divisões especializadas em funções distintas está presente em todas as empresas da presente pesquisa. Também é característica dessas organizações o fluxo de informações de cima para baixo que possuem efetividade muito superior à de baixo para cima. Esses elementos diminuem ou eliminam gargalos de origem na coleta de dados.

\section{ANÁLISE DOS RESULTADOS}

Nesta parte são apresentados os resultados obtidos com as entrevistas realizadas. Cabe notar que por ser uma pesquisa qualitativa baseada em estudo de casos, as conclusões a que se chega não podem ser extrapoladas a outras empresas.

Dentre os modelos desenvolvidos pelos autores pesquisados, optou-se pelo modelo de Voss apresentado por Barros Neto (1999) que ficou próximo à realidade do padrão revelado no decorrer da revisão de literatura. Nesse modelo existem quatro etapas distintas. Na primeira o autor 
A Participação do Nível Operacional no Processo de Formulação de Estratégias.

argumenta que o Set-Up refere-se a fatores motivacionais da formulação de estratégias, define responsabilidades e necessidade de comprometimento. Na segunda fase (processo) existe a busca pelo indivíduo que centralizará as ações na condição de líder de um grupo e, também, há a definição de quem participará do processo. O terceiro momento ( $1^{\mathrm{a}}$ análise) é de análise ambiental para definição de atividades específicas. Na quarta e última fase ( $2^{\mathrm{a}}$ análise) desenvolve-se uma visão de futuro que seria a ideal, planos de ação e operação e apresentação do produto para aprovação superior. Ressalte-se que para o presente estudo a fase de implementação não é considerada.

\subsection{ELABORAÇÃO DO MODELO DE FORMULAÇÃO DE ESTRATÉGIAS NA ÓTICA PARTICIPATIVA}

O modelo apresentado por Barros Neto (1999) em sua análise de Voss, serviu de base para elaboração do modelo deste artigo observando-se aspectos participativos para apresentação dos resultados deste estudo, assim, o mesmo foi considerado uma adaptação. Após análise dos dados colhidos em campo foi possível identificar os principais elementos que cerceiam fatores participativos na etapa de formulação de estratégias. Dessa forma, o estudo segue sob a égide da análise de dez fatores presentes nas cinco fases identificadas, já incluindo nova fase sugerida para o processo. Portanto, além de se apresentar as fases identificadas no processo da etapa de formulação de estratégias, apresentam-se os fatores vinculados a elas com as principais evidências empíricas durante a discussão sobre os mesmos. Tal estrutura permite trazer a cientificidade costumeiramente ausente nas discussões do tema conforme discutido no corpo do artigo. A seguir discute-se em separado cada fase ou fator, inerente à formulação de estratégias.

\subsection{FASE PREPARATÓRIA (IDENTIFICADA DURANTE A PESQUISA)}

Esta fase consta das reuniões, workshops e palestras sobre o que se espera das estratégias e dos participantes. A primeira questão buscou entender se as organizações pesquisadas realizam reuniões, workshops e palestras visando a preparação dos funcionários para o processo de gestão estratégica com ênfase na fase de formulação. A totalidade dos participantes da pesquisa concorda que a preparação do pessoal é o meio mais importante para atingir os objetivos de longo prazo (estratégias) de suas empresas. O entrevistado de nível tático da Empresa "A” entende que o momento preparatório é vital já que “... favoreceria a todos buscarem melhor argumentação, melhor posicionamento sobre o que será tratado.”. Diz ainda que “... Hoje, infelizmente, não temos muitas

Revista Ibero-Americana de Estratégia RIAE, São Paulo, v. 10, n. 1, p. 170-194, jan/abr. 2011. 
pessoas que dominam o assunto de estratégia. Dessa forma, a empresa teria que buscar meios de que todos conhecessem, não apenas essas atividades estratégicas, mas também todo o órgão...”. A congruência dos depoimentos é impressionante, independente do tamanho da empresa ou do nível hierárquico pesquisado. Mintzberg e Quinn (2001) alertam que o processo estratégico não é composto apenas por formulação e execução, corroborando com os dados levantados no estudo, enquanto, Mintzberg et al (2000) argumentam que pessoas com posse de informações são importantes nesse contexto.

\subsection{INICIAÇÃO (SET-UP)}

\section{a) Motivação para formular as estratégias}

Em qualquer atividade administrativa há a necessidade de motivação para que o processo estratégico e consequentemente suas etapas ocorram. Na etapa de formulação de estratégias não seria diferente. Ainda assim, apenas em três empresas (Empresas "A", "B" e "C") se registrou a participação do nível operacional. O entrevistado de nível estratégico da Empresa "B" afirmou que a realização da formulação das estratégias em sua empresa foi provocada por outra vinculada ao sistema ao qual ela pertence. Para tanto ele comentou que “... tem sido uma provocação do próprio sistema que o planejamento estratégico seja elaborado em conjunto, então esse que está sendo operacionalizado hoje, veio de uma discussão anterior do sistema de que a empresa deveria estar inserida no mesmo e aí começou a se criar uma cultura de 2008 para 2009 e já está se trabalhando para 2010...". Dessa forma, resta evidente que os profissionais de nível operacional não tiveram participação quando da motivação para formular as estratégias já que mal tinham conhecimento das atividades que estavam sendo desenvolvidas. Isso contribuiria para a criação de metas atingíveis e para o melhor entendimento do que é proposto pela cúpula por parte de todos os colaboradores. Esse argumento corrobora com Panegalli (2004) pelo qual a compreensão, a possibilidade de medir e comunicar conteúdos estratégicos por toda a organização contribui para o eficaz alcance de objetivos.

b) Participação na seleção do local para formular estratégias

Neste tópico, o objetivo de análise é a participação dos funcionários que atuam no nível operacional na seleção do local das reuniões onde serão discutidas as estratégias a serem adotadas 
A Participação do Nível Operacional no Processo de Formulação de Estratégias.

pelas empresas. À exceção de um respondente, todos os demais afirmaram que a escolha é feita em nível de diretoria sem a participação dos demais colaboradores. Na Empresa "C" a cultura parece ser extremamente top-down nesse quesito. A participante de nível estratégico, por exemplo, até entende que poderia ajudar, contudo não acha importante. Ela argumenta que "Não acho que seria importante. Lógico que seria muito bom poder sugerir um bom local e etc. Existem alguns órgãos que fazem isso. Nosso fiscalizador, por exemplo, faz.”. O participante de nível operacional corrobora com seus colegas dizendo que "Não, os funcionários não participam dessa etapa." e completa seu argumento relatando que "Eu acho que isso não seria interessante porque poderia gerar “oba-oba”. Pessoas poderiam querer aproveitar o momento para bagunçar a atividade...”.

\section{c) Convocação dos envolvidos}

A participação do nível operacional nessa etapa, quando ocorre, sofre diversas ações de controle e obedece a critérios de passividade do profissional. Em apenas uma das organizações pesquisadas (Empresa “D”) o sistema tenta ser mais democrático no que diz respeito à convocação do pessoal de nível operacional para participar de eventos da etapa de formulação de estratégias. Na Empresa "E" houve ocasião em que se tentou contar com a participação do nível operacional, porém com falhas de origem, já que o profissional sabia do evento, mas não sabia o que seria tratado. A informação parte do entrevistado de nível operacional alegando que “... o comunicado foi verbal, não houve documento formalizando nada." e conclui dizendo "... Foi realmente informado que haveria a reunião, onde seria, quando e só”. O participante de nível estratégico foi bem objetivo ao afirmar que a reunião ocorre em nível de cúpula e depois deveria ser pulverizada na organização. Dessa forma, o informe sobre o processo estratégico é repassado ao operacional de maneira passiva. O entrevistado de nível estratégico confirma essa argumentação dizendo que "Na verdade, como o processo envolve os líderes, coordenadores e assessorias, essas pessoas têm a função de passar tudo para suas equipes, através de reuniões com a mesma.”. Autores como Maximiano (1995) e Oliveira e Castelo (2005) apresentam argumentos de que a comunicação é fator primordial para efetividade das ações organizacionais inclusive a estratégia. Isso motivaria e aumentaria o comprometimento de todos, corroborando com Almeida (2000), Wright, Kroll e Parnell (2000) e Senge (1999) que viam esses aspectos como fundamentais para eficiência em atividades, incluindo-se, aí, as estratégicas.

Revista Ibero-Americana de Estratégia RIAE, São Paulo, v. 10, n. 1, p. 170-194, jan/abr. 2011. 


\subsection{PROCEDIMENTOS DE FORMULAÇÃO (PROCESSO)}

a) Realização de palestras explicativas

Em todos os níveis das organizações pesquisadas há o entendimento de que eventos elucidativos ao processo estratégico favorecem a consecução da etapa de formulação de estratégias uma vez que os participantes passam a estar interados do assunto. No entanto, em apenas duas (Empresas "B" e "D") foi detectado esse elemento. O entrevistado da Empresa "D" possui ideais e disposição democráticos atentando-se às limitações impostas pela entidade. Com posição no nível estratégico o mesmo procura passar aos seus subordinados, informações que os posicionem previamente das ações organizacionais com o seguinte comentário "Isso é feito a partir do momento em que eu reúno os funcionários para mantê-los inteirados do que está acontecendo, assim, eles passam a entender qual é o seu papel na empresa...”. Contudo, rememorando as falas anteriores desse participante, resta evidente que não há na organização, ao menos formalizado, um sistema que identifique e resolva problemas ligados à falta de conhecimento sobre estratégia por parte dos funcionários.

b) Realização de oficinas de trabalho ou reuniões por grupo para elaborar ideias

Esse elemento busca entender a ocorrência de atividades que reúnam os envolvidos na etapa de formulação de estratégias nas quais germinem os sentimentos organizacionais que se transformarão em objetivos ou metas estratégicas de maneira focalizada. A participação ativa ocorre à medida que a empresa convoca seus funcionários, incluindo o nível operacional, a emitirem opinião em conjunto com profissionais de todos os níveis a fim de reduzir lacunas e estabelecer sugestões estratégicas factíveis. Das organizações pesquisadas, apenas três (Empresas "B", "C" e "E”) apresentam esse perfil na visão dos entrevistados. O discurso do entrevistado da Empresa "D" (nível estratégico) é contundente sobre esse fator. Apesar de adotar uma postura democrática o mesmo comenta que “... A formulação em si é feita pelo colegiado e pela Diretoria...”.

c) Realização de reunião dos grupos para sintetizar ideias e seleção das melhores ideias

As mesmas organizações que trabalham o fator anterior (Empresas "B", "C" e "E") procuram inteirar o profissional de nível operacional no momento de unificar os esforços de grupos 
A Participação do Nível Operacional no Processo de Formulação de Estratégias.

focalizados no que se pode chamar de formulação macro de estratégias. Esse elemento analisa a participação do profissional de nível operacional na atividade de compilar o que se discutiu em grupos distintos para concretizar a etapa de formulação de estratégias. Essa fase foi bem relatada pelo entrevistado de nível estratégico da Empresa "B" quando informa que após o trabalho em grupos emergiram vinte ideias que posteriormente, com a participação de todos os envolvidos, foram transformadas em apenas dez itens. Esses poderiam vir a se tornar metas conforme alega que “... de vinte ideias foi feita uma diminuição para no máximo dez metas para a empresa...” e complementa dizendo “... Tudo isso com o objetivo de se atingir ao menos uma meta, que já se consideraria um grande feito...".

\subsection{PROCESSO DECISÓRIO (PRIMEIRA ANÁLISE)}

a) Participação nas correções e ajustes

O presente fator está para a estratégia como o controle está para a ciência da Administração uma vez que pode colaborar com eliminação de falhas antes que elas ocorram. Apesar da importância de se poderem minimizar impactos negativos que uma decisão mal orientada pode ocasionar, nenhuma das empresas pesquisadas apresentou pontos de participação do profissional de nível operacional nessa questão. No nível estratégico da Empresa "E” entende-se o elemento como uma questão fechada já que “... a Diretoria entende que o coordenador está trazendo tudo o que o setor demanda...". A discussão apresentada remete às argumentações de Maximiano (1995) de que um dos fatores de sucesso do Japão foi justamente apoiar a participação dos funcionários nas decisões estratégicas. Contudo, após levantadas as ideias que se tornariam estratégias, os funcionários de nível operacional, como o entrevistado, não foram chamados para colaborar nas correções e ajustes. Ainda assim, existem autores que apóiam o esquema top-down como Wright, Kroll e Parnell (2000) que entendem ser da alta gerência a responsabilidade por decidir, porém, com o suporte do restante do corpo funcional e é aí que reside a confusão.

\subsection{PROCEDIMENTOS PÓS-FORMULAÇÃO (SEGUNDA ANÁLISE)}

a) Fechamento do planejamento estratégico e apresentação à Diretoria - feedback 
No decorrer das entrevistas ficou evidente em relação aos argumentos dos principais autores de Estratégia que a etapa de formulação é um processo como outro qualquer, ou seja, possui início, meio e fim. O encerramento da atividade é composto por definições sobre tudo o que se discutiu e pelo produto dos esforços de grupos distintos até se chegar à abordagem sistêmica. Apesar de ser um elemento importante, apenas uma das organizações pesquisadas (Empresa "E") apresentou relato de que o elemento está presente no que diz respeito à participação do nível operacional. $\mathrm{O}$ entrevistado de nível operacional da Empresa "B" apresenta argumento simples, mas que confirma o que fica intrínseco na fala do nível estratégico. O mesmo diz que “... Essas metas foram compiladas pelo órgão maior do sistema, enviadas ao superintendente da instituição e feito encaminhamento ao gerente. Não tivemos mais contato.”. Essa passagem revela outro problema estrutural relatado por Mintzberg et al. (2000) no qual pode haver uma base inadequada e os requisitos culturais podem estar sendo negligenciados, ou seja, se a cúpula não entende direito o processo e colhe informações sem retornar é difícil contar com a participação dos indivíduos de base.

b) Informação de resultados - acatamento ou não de idéias

A participação ativa do nível operacional na etapa de formulação de estratégias seria concluída no momento em que houvesse retorno ao mesmo sobre as proposições feitas durante as outras fases presentes na atividade. Essa atividade poderia ser enquadrada como parte do controle da formulação uma vez que forneceria subsídios sobre a linha de pensamento a ser adotada para futuras incursões. Ainda assim, apenas em três organizações pesquisadas (Empresas "B", "D" e “E”), esse fator foi considerado presente. O entrevistado de nível estratégico da Empresa "A", por exemplo, alega que quando era Diretor, sempre procurou manter seus funcionários informados a respeito de assuntos diversos. O problema residia na questão estratégia que conforme é dito pelo entrevistado “... como não vinha feedback dos motivos de uma ideia ter sido aceita ou não, isso eu não retransmitia.". Nesse contexto, se observa que orientações como as de Furtado (2008) não são consideradas, passando a ideia de que os funcionários fazem parte do processo sem, no entanto, incentivar participação em todas as ações. 
A Participação do Nível Operacional no Processo de Formulação de Estratégias.

\subsection{DEMAIS INFERÊNCIAS EM RELAÇÃO AOS DADOS COLHIDOS}

No decorrer de todas as entrevistas os participantes mostraram-se solidários à participação do nível operacional na formulação de estratégias, mesmo reconhecendo em suas falas mais contundentes que aquilo não ocorria na prática. Importante ressaltar que os superiores ou profissionais que estão em nível tático e estratégico reconhecem a importância da participação aqui pregada. Uma das questões da pesquisa é explorar se existe distribuição de poder para que a participação seja ativa. O entrevistado de nível estratégico da Empresa "A" entende que não há como alguém contribuir de fato com a atividade estratégica se não tiver voz ativa, contudo, reconhece que a estrutura política cria um viés nessa questão. O entrevistado de nível operacional da Empresa "B" reconhece que durante as reuniões que participou esteve em contexto ativo, ou seja, falava e era ouvido, entretanto, afirma que não houve abertura para participar de decisão nenhuma. O entrevistado de nível tático da Empresa "C" afirma que a estrutura é autocrata e não há abertura para o nível operacional ter poder, já que é a cúpula que resolve as questões estratégicas. A Empresa "D" e a Empresa "E" são fechadas a presente questão e mantém postura que possibilita apenas a participação passiva.

É pacífico entre quase todas as opiniões das empresas pesquisadas que o profissional de nível operacional possui contribuições a dar e é importante para as ações estratégicas tal qual discutido ao longo da revisão de literatura da presente pesquisa. Para exemplificar essa argumentação remete-se à entrevista do participante de nível estratégico da Empresa "A" que lembra que esse funcionário lida com o cliente na ponta e, por esse motivo, conhece as fraquezas de algum processo. O participante de nível tático da Empresa "C" diz que o profissional de nível operacional é fundamental para que a formulação de estratégias aconteça. O entrevistado de nível estratégico da Empresa "D” emite sua opinião dizendo que "é o nível operacional que ouve os anseios dos clientes e, participando da formulação de estratégias, poderia expor isso". Outra inferência que merece destaque é o entendimento dos entrevistados de que o profissional de nível operacional melhora seu desempenho caso participe de processos de formulação estratégica. Essa discussão traz anseios e afirmações de todos os níveis. Na opinião do entrevistado de nível tático da Empresa "A" a estrutura participativa possibilita o crescimento organizacional. O entrevistado de nível operacional da Empresa "C", por exemplo, fala em elevar a autoestima e do crescimento da qualidade do serviço prestado.

Revista Ibero-Americana de Estratégia RIAE, São Paulo, v. 10, n. 1, p. 170-194, jan/abr. 2011. 


\subsection{MATRIZ DOS PRINCIPAIS FATORES OU ELEMENTOS DESCOBERTOS}

Baseado no modelo elaborado e nos dados colhidos pode-se apresentar uma matriz que ilustra os principais fatores ou elementos que se relacionam com a participação ou não do nível operacional em cada fase da formulação na visão dos três níveis hierárquicos conforme pode ser visualizado na Tabela 1 a seguir. As ações organizacionais identificadas na etapa de formulação de estratégias apresentadas nesta tabela foram detalhadas empiricamente, uma a uma.

Tabela 1 - Matriz dos principais fatores ou elementos descobertos e sua relação com a participação do nível operacional na formulação de estratégias

\begin{tabular}{|c|c|c|c|c|c|c|c|c|c|c|c|c|c|c|c|c|c|c|c|c|c|c|c|c|}
\hline \multirow{3}{*}{$\begin{array}{l}\text { EMPRESA E } \\
\text { ANALISADO } \\
\text { FATOR/ELEMENTO } \\
\begin{array}{l}\text { Reuniões, workshops e palestras } \\
\text { sobre o que se espera das estratégias } \\
\text { e dos participantes }\end{array}\end{array}$} & \multicolumn{5}{|c|}{ EMPRESA A } & \multicolumn{5}{|c|}{ EMPRESA B } & \multicolumn{5}{|c|}{ EMPRESA C } & \multicolumn{4}{|c|}{ EMPRESA D } & \multicolumn{5}{|c|}{ EMPRESA E } \\
\hline & \multirow{2}{*}{\begin{tabular}{l|l}
$\mathrm{VO}$ \\
$\mathrm{N}$
\end{tabular}} & \multicolumn{2}{|c|}{ VT } & \multicolumn{2}{|c|}{$\mathrm{VE}$} & \multicolumn{2}{|c|}{ Vo } & & \multicolumn{2}{|c|}{$\mathrm{VE}$} & \multicolumn{2}{|c|}{$\mathrm{VO}$} & VT & \multicolumn{2}{|c|}{$\mathrm{VE}$} & \multirow{2}{*}{ VO } & \multirow{2}{*}{\begin{tabular}{|l|}
\multicolumn{2}{|c|}{ VT } \\
\\
\end{tabular}} & \multicolumn{2}{|c|}{ VE } & \multicolumn{2}{|c|}{ VO } & VT & \multirow{2}{*}{\multicolumn{2}{|c|}{\begin{tabular}{|l|}
$\mathrm{VE}$ \\
$\mathrm{N}$
\end{tabular}}} \\
\hline & & $\mathrm{N}$ & & $\mathrm{N}$ & & $\mathrm{N}$ & & & & & $\mathrm{N}$ & & $\mathrm{N}$ & $\mathrm{N}$ & & & & $\mathrm{N}$ & & & & & & \\
\hline Motivação para formular estratégias & $\mathrm{N}$ & & $\mathrm{S}$ & & $\mathrm{S}$ & & $\mathrm{S}$ & & & $\mathrm{S}$ & & $\mathrm{S}$ & S & tis & $\mathrm{S}$ & & & $\mathrm{N}$ & & & $\begin{array}{lll}\mathrm{S} & \mathrm{I} \\
\end{array}$ & $\mathrm{N}$ & $\bar{N}$ & $\mathrm{~N}$ \\
\hline $\begin{array}{l}\text { Participação na seleção do local para } \\
\text { formular estratégias }\end{array}$ & $\mathrm{N}$ & $\mathrm{N}$ & & $\mathrm{N}$ & & & & & & $\mathrm{S}$ & $\mathrm{N}$ & & S & $\mathrm{N}$ & & & & $\mathrm{N}$ & & $\mathrm{N}$ & & $\mathrm{N}$ & $\mathrm{N}$ & N \\
\hline Convocação dos envolvidos & $\mathrm{N}$ & $\mathrm{N}$ & & $\mathrm{N}$ & & & $\mathrm{S}$ & & & $\mathrm{S}$ & $\mathrm{N}$ & & $\mathrm{N}$ & $\mathrm{N}$ & & & & $\mathrm{N}$ & & $\mathrm{N}$ & & $\mathrm{N}$ & $\mathrm{N}$ & $\mathrm{N}$ \\
\hline Realização de palestra explicativa & $\mathrm{N}$ & $\mathrm{N}$ & & $\mathrm{N}$ & & $\mathrm{N}$ & & & & $\mathrm{S}$ & $\mathrm{N}$ & & $\mathrm{N}$ & $\mathrm{N}$ & & & & & $\mathrm{S}$ & $\mathrm{N}$ & & $\mathrm{N}$ & $\overline{\mathrm{N}}$ & $\mathrm{N}$ \\
\hline $\begin{array}{l}\text { Realização de oficinas de trabalho ou } \\
\text { reuniões por grupo para elaborar } \\
\text { ideias }\end{array}$ & $\mathrm{N}$ & $\mathrm{N}$ & & $\mathrm{N}$ & & & $\mathrm{S}$ & & & $\mathrm{S}$ & & $\mathrm{S}$ & S & $\mathrm{N}$ & & & & $\mathrm{N}$ & & & $\mathrm{S}$ & S & $\mathrm{N}$ & N \\
\hline $\begin{array}{l}\text { Realização de reunião com todos os } \\
\text { grupos para sintetizar ideias }\end{array}$ & $\mathrm{N}$ & $\mathrm{N}$ & & $\mathrm{N}$ & & & $\mathrm{S}$ & & & $\mathrm{S}$ & & $\mathrm{S}$ & S & $\mathrm{N}$ & & & & $\mathrm{N}$ & & & $\mathrm{S}$ & S & $\mathrm{N}$ & N \\
\hline Participação nas correções e ajustes & $\mathrm{N}$ & $\mathrm{N}$ & & $\mathrm{N}$ & & $\mathrm{N}$ & & & $\mathrm{N}$ & & $\mathrm{N}$ & & $\mathrm{N}$ & $\mathrm{N}$ & & & & $\mathrm{N}$ & & $\mathrm{N}$ & & $\mathrm{N}$ & $\mathrm{N}$ & $\mathrm{N}$ \\
\hline $\begin{array}{l}\text { Fechamento do planejamento } \\
\text { estratégico e apresentação à Diretoria } \\
\text { - feedback }\end{array}$ & $\mathrm{N}$ & $\mathrm{N}$ & & $\mathrm{N}$ & & $\mathrm{N}$ & & & $\mathrm{N}$ & & $\mathrm{N}$ & & $\mathrm{N}$ & $\mathrm{N}$ & & & & $\mathrm{N}$ & & $\mathrm{N}$ & & $S$ & $\mathrm{~S}$ & $\mathrm{~N}$ \\
\hline $\begin{array}{ll}\text { Informação de resultados } & - \\
\text { acatamento ou não de ideias } & \end{array}$ & $\mathrm{N}$ & $\mathrm{N}$ & & $\mathrm{N}$ & & $\mathrm{N}$ & & & & $\mathrm{S}$ & $\mathrm{N}$ & & $\mathrm{N}$ & $\mathrm{N}$ & & & & & $\mathrm{S}$ & $\mathrm{N}$ & & $S$ & $\mathrm{~S}$ & $\mathrm{~N}$ \\
\hline
\end{tabular}

No entanto, a participação do nível operacional é percebida apenas em sete dessas, conforme entendimento dos entrevistados e considerando a maioria de opiniões congruentes (mínimo de 50\% por empresa), sendo:

- $\quad$ Motivação para formular estratégias (3 empresas);

- $\quad$ Participação na seleção do local para formular estratégias (2 empresas);

- $\quad$ Convocação dos envolvidos (1 empresa);

- $\quad$ Realização de palestra explicativa (2 empresas);

Revista Ibero-Americana de Estratégia RIAE, São Paulo, v. 10, n. 1, p. 170-194, jan/abr. 2011. 
A Participação do Nível Operacional no Processo de Formulação de Estratégias.

- $\quad$ Realização de oficinas de trabalho ou reuniões por grupo para elaborar ideias (3 empresas);

- Realização de reunião com todos os grupos para sintetizar ideias (3 empresas);

- $\quad$ Informação de resultados - acatamento ou não de ideias (2 empresas).

Nenhum fator ou elemento foi unânime no que se refere à participação do profissional de nível operacional na etapa de formulação de estratégias nas empresas pesquisadas.

\subsection{IDENTIFICAÇÃO GRÁFICA DO GRAU DE PARTICIPAÇÃO DO OPERACIONAL NA ETAPA DE FORMULAÇÃO DE ESTRATÉGIAS}

Uma vez levantados os principais fatores ou elementos inerentes às fases identificadas no modelo elaborado na presente dissertação, tornou-se possível avaliar o nível de participação do operacional na formulação de estratégias nas empresas pesquisadas.

De posse dos dados, com a concepção de novo modelo de formulação de estratégias, após discussão dos fatores ou elementos um a um e alimentação da matriz concebida para esta dissertação, construiu-se o instrumento denominado “MEDIDOR DE PARTICIPAÇÃO” conforme (Tabela 2) e (Gráfico 1).

Tabela 2 - Medidor de participação.

\begin{tabular}{|l|c|c|c|c|c|c|}
\hline EMPRESA & A & B & C & D & E & $\begin{array}{c}\text { MÉDIA DAS } \\
\text { ORGANIZAÇÕES }\end{array}$ \\
\hline Preparatória & 0 & 0 & 0 & 0 & 0 & 0,0 \\
\hline Iniciação & 1 & 1 & 1 & 0 & 0 & 0,6 \\
\hline Procedimentos de formulação & 0 & 1 & 1 & 1 & 1 & 0,8 \\
\hline Processo decisório & 0 & 0 & 0 & 0 & 0 & 0,0 \\
\hline Procedimentos pós-formulação & 0 & 1 & 0 & 1 & 0 & 0,4 \\
\hline Grau de participação & $\mathbf{1}$ & $\mathbf{3}$ & $\mathbf{2}$ & $\mathbf{2}$ & $\mathbf{1}$ & $\mathbf{1 , 8}$ \\
\hline
\end{tabular}

Fonte: Elaborado pelo autor

O presente instrumento mede o grau de participação do nível operacional na etapa de formulação das estratégias nas empresas pesquisadas. A participação identificada em cada fase equivale a 1 ponto em uma escala que vai de 0 a 5. As instituições de A a E são entidades de classe no DF.

* As fases foram identificadas durante a pesquisa bibliográfica e de campo e as nomenclaturas compõem o modelo produzido pelo autor baseado em Barros Neto (1999) que apresenta o modelo de Voss (1992).

Revista Ibero-Americana de Estratégia RIAE, São Paulo, v. 10, n. 1, p. 170-194, jan/abr. 2011. 
MEDIDOR DE PARTICIPAÇÃO

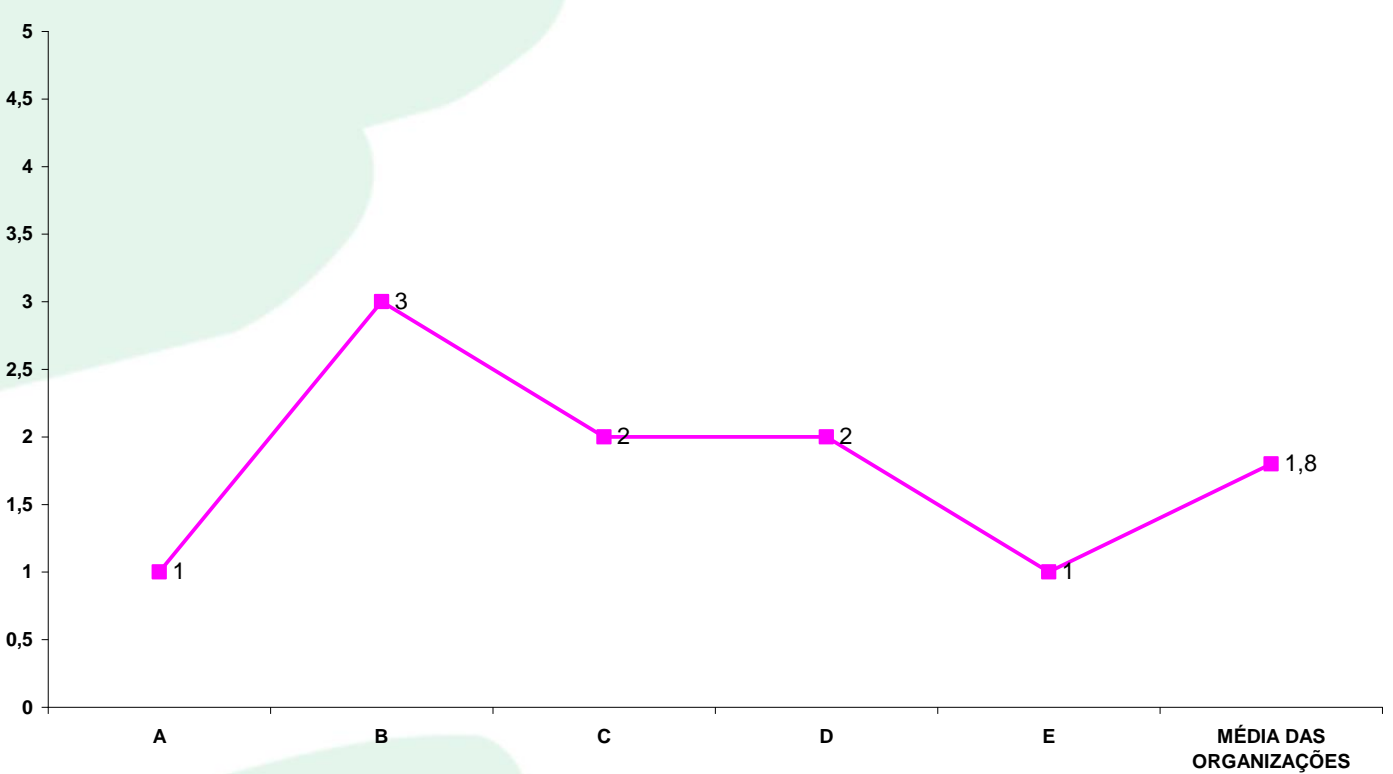

Gráfico 1 - Representação gráfica da tabela 4

Fonte: Elaborado pelo autor.

\section{CONCLUSÃO}

O exposto no Item 4 permite concluir que, unanimemente, todos os níveis hierárquicos das empresas pesquisadas concordam que o profissional de nível operacional possui contribuições a dar e é importante para as etapas do processo estratégico, principalmente na etapa de formulação. Para exemplificar esta afirmação transcrevem-se alguns depoimentos a respeito como "esse funcionário lida com o cliente na ponta e, por esse motivo, conhece as fraquezas do nosso processo"; “... o profissional de nível operacional é fundamental para que a formulação de estratégias aconteça”; “é o nível operacional que ouve os anseios dos clientes e que, participando da formulação de estratégias, poderia expor isso"; e “... que o profissional de nível operacional melhora seu desempenho caso participe de processos de formulação estratégica”. Esses pensamentos corroboram com os de autores importantes e pesquisadores como Maximiano (1995), Wright, Kroll e Parnell (2000), Panegalli (2004) e Furtado (2008).

Nesse sentido, Mintzberg \& Quinn (2001) abordam a essência operacional onde se tem a necessidade de ajuste do trabalho para tratar distúrbios da organização. Afirmam esses autores, ao tratar da função gerencial, que as tarefas que envolvem um gerente são complicadas e difíceis. Isto 
A Participação do Nível Operacional no Processo de Formulação de Estratégias.

porque este está, na maioria das vezes, sobrecarregado com atividades que acaba realizando sem profundidade. Assim, o uso de pessoas em vez de apenas informações seria o modelo ideal para conseguir fazer com que as tarefas, atividades ou ações acontecessem com redução de trabalho direto ao gerente. Há exemplos de empresas que formulam estratégias com o objetivo de se posicionar melhor no mercado e atingir metas. Em muitas ocasiões, esses objetivos são impossíveis de serem alcançados, mesmo porque as capacidades e limitações dos atores e da empresa podem estar sendo desprezadas.

Todavia, o reconhecimento da importância de um processo estratégico participativo em todos os níveis hierárquicos das organizações não é suficiente para que o mesmo seja posto em prática. Como o nível operacional nas organizações pesquisadas participa de forma tangencial em apenas algumas etapas, isso quando participa de alguma, da formulação do processo estratégico, o mesmo não tem conhecimento dessa atividade de maneira sistêmica. Alguns entrevistados de nível tático e operacional chegaram a alegar que os detentores de cargos de cúpula, em muitos casos, sequer conhecem as ferramentas estratégicas. Senge (1999) afirma que para colaborar verdadeiramente o indivíduo deve estar comprometido em um processo. Contudo, as empresas que elaboraram o planejamento estratégico com a participação dos seus funcionários de níveis diversos motivaram essa participação até o momento da compilação dos dados. Dessa parte em diante não houve interesse na participação do nível operacional para passar as ideias ao papel. Tal argumentação corrobora com a preocupação de Mintzberg e Quinn (2001) de que metas e desafios não compreendidos fatalmente não serão eficazes.

No que concerne à existência de fatores que viabilizem ações facilitadoras, como demonstrado durante a discussão de resultados, foram identificadas dez ações inerentes às cinco empresas pesquisadas. Contudo não contam com a participação do nível operacional em sua totalidade e tampouco em todas as empresas (Tabela 1). As atividades de cunho estratégico são diversas e invariavelmente executadas por profissionais de nível operacional. Sendo assim, com base em Alday (2000), podemos inferir que o funcionário, apesar de ser de nível operacional, executa ações estratégicas voltadas à criação de competitividade no mercado. Isso também corrobora com os apontamentos de Wright, Kroll e Parnell (2000) no sentido de que a alta gerência necessita mais das pessoas conforme aumenta a importância de uma ou mais de suas atividades. Autores como Lemos, Lima, Desconci e Ehlers (2004) apresentam argumentos congruentes de que o pessoal envolvido em processo estratégico deve estar focado em objetivos e metas.

Relativo à distribuição de poder com o objetivo de tornar a participação ativa, em todas as entidades de classe pesquisadas, a estrutura fortemente politizada e tradicional não permite tal 
atividade conforme visto no decorrer da discussão de resultados. Apoiar a construção do processo que norteará a formulação de estratégias demanda certo grau de poder para tornar a participação do nível operacional ativa e não apenas de ouvinte. A participação no processo decisório aumenta o poder de comprometimento, compreensão e eficácia de uma estratégia por parte dos envolvidos (PANEGALLI, 2004). Este talvez seja o principal achado do trabalho para revelar porque o nível operacional, apesar do elevado reconhecimento de sua importância no processo estratégico, não é incentivado a participar do mesmo. Os principais comentários dos entrevistados a respeito foram: “... não há como alguém contribuir de fato com a atividade estratégica se não tiver voz ativa (reconhece que a estrutura política cria um viés nessa questão)”; “... às vezes ele era ouvido, entretanto, não houve abertura para participar de decisão nenhuma”; “... a estrutura é autocrata e não há abertura para o nível operacional ter poder, já que é a cúpula que resolve as questões estratégicas".

\section{CONTRIBUIÇÕES, EXTENSÕES E LIMITAÇÕES.}

A integração entre as disciplinas de Administração (Administração Estratégica, Recursos Humanos, Organização e Métodos, etc.) percebida durante toda a pesquisa e os resultados ora apresentados traz à tona algumas relações merecedoras de novas pesquisas. Muitos participantes alegam falha no processo em virtude do pouco entendimento pelo nível operacional do que é buscado pela cúpula de suas empresas ao traçar metas estratégicas. Nota- se a necessidade de pesquisas que verifiquem as relações existentes entre a efetividade do planejamento estratégico com a participação do nível operacional em sua formulação. Outro fator fortemente discutido pelos entrevistados foi a questão motivacional e a autoestima em relação à participação do profissional de nível operacional na etapa de formulação estratégica. Abre-se margem para pesquisa relacionando esses elementos de maneira multidisciplinar já que se têm fatores puramente de gestão e fatores psicológicos.

Como principais contribuições da pesquisa se destacam a elaboração de um modelo de processo de formulação estratégica, baseado no estudo de Barros Neto (1999) que elenca o modelo de Voss no qual se incluiu nova fase descoberta a partir dos dados colhidos. A descoberta dos principais fatores que poderiam viabilizar a participação do nível operacional na etapa de formulação de estratégias possibilitou a construção de ferramentas. Trata-se da "matriz de principais fatores ou elementos" e o "medidor de participação" que ilustram os dados e facilitam

Revista Ibero-Americana de Estratégia RIAE, São Paulo, v. 10, n. 1, p. 170-194, jan/abr. 2011. 
A Participação do Nível Operacional no Processo de Formulação de Estratégias.

conclusões. Notou-se que ambas as ferramentas poderão ser adaptadas e utilizadas em outras pesquisas para facilitar a inferência do pesquisador e, em termos de gestão, servem para medir o grau de participação oferecido por qualquer empresa. Sugere-se replicar a pesquisa aumentando a quantidade de empresas e considerando ao menos, duas finalidades distintas como, por exemplo, cinco entidades de classe sem fins lucrativos e cinco bancos para se poder comparar a realidade em segmentos diferentes.

Um dos maiores limitadores da pesquisa foi a fragmentação das bases teóricas. Os temas discutidos (participação, administração participativa, administração estratégica, formulação de estratégias, dentre outros) normalmente são tratados em separados ou, quando em conjunto, de maneira insipiente. Outro limitador é a inexistência, dentro do aporte acadêmico pesquisado, de pesquisas que verifiquem a participação do nível operacional na etapa de formulação de estratégias empiricamente. Esse segundo deixa claro que, apesar de o assunto estratégia estar fortemente discutido e em alguns casos esgotado, esse é um elemento que oferece amplo campo para desenvolvimento e fortalecimento de inferências e também de críticas além de ser multidisciplinar. Não obstante, a principal contribuição da pesquisa é trazer em seu conteúdo o alicerce empírico do qual o tema é carente quando se trata de literatura.

\section{REFERÊNCIAS}

Almeida, A. F. Planejamento estratégico e proatividade: um estudo de caso em duas unidades regionais do Banco Central do Brasil. Revista de Administração Contemporânea, Curitiba, v. 4, n. 3, p. 177-199, set./dez. 2000.

Almeida, L. B.; Machado, E. A.; Raifur, L.; Nogueira, D. R. A Utilização do orçamento como ferramenta de apoio à formulação de estratégia, de controle e de interatividade: um estudo exploratório nas cooperativas agropecuárias da região sul do Brasil. Revista Contabilidade Vista \& Revista, v. 20, n. 3, p. 65-99, jul./set. 2009.

Alday, H. E. C. O Planejamento estratégico dentro do conceito de administração estratégica. Revista da Faculdade Católica de Administração e Economia, Curitiba, v. 3, n. 2, p. 9-16, maio/ago. 2000.

Bardin, L. Análise de conteúdo. Lisboa: Edições 70, 1977.

Revista Ibero-Americana de Estratégia RIAE, São Paulo, v. 10, n. 1, p. 170-194, jan/abr. 2011. 
Barros Neto, J. P. Proposta de um modelo de formulação de estratégias de produção para pequenas empresas de construção habitacional. 1999. $326 \mathrm{f}$. Tese de doutoramento - Escola de Administração, PPGA. Universidade Federal do RGS, Porto Alegre, 1999.

Belo, M. A. C.. Sistemas tradicionais e estratégias de desenvolvimento. Revista da FESP: periódico de diálogos científicos. [online]. 2010, vol. 1, n. 7, p. 07-19. Texto disponível em: http://www.revistadafesp.com.br. Último acesso: (26 de março de 2011). ISSN: 1982-0895.

Brunstein, J. Da estratégia individual à ação coletiva: grupos de suporte e gênero no contexto da gestão da diversidade. RAE-eletrônica, v. 8, n. 2, Art. 9, jul./dez. 2009.

Costa, B. K.; Boaventura, J. M. G.; Barreto, L. M. T. S. Formulação de estratégias no turismo: um estudo em órgãos municipais do Estado de São Paulo. Turismo em Análise, v. 21, n. 1, abr. 2010.

Ferreira, J. C. B.; Vilamaior, A. G.; Gomes, B. M. A. O poder nas organizações: conceitos, características e resultados. Revista do Instituto Superior Presidente Tancredo Neves, 15 p., dez. 2005.

Fleury, M. T. L.; Fischer, R. M. Cultura e poder nas organizações. 2. ed. São Paulo: Atlas, 1996.

Foucault, M. Microfísica do poder. 10. ed. Rio de Janeiro: Graal, 1992.

Furtado, R. A. Retomando o debate sobre gestão participativa nas empresas a partir da contribuição da teoria da estruturação. Rio de Janeiro: Anais do XXXII Encontro ENANPAD. ANPAD, set. 2008, 15 p.

Gil, A. C. Métodos e técnicas de pesquisa social. 4. ed. São Paulo: Atlas, 1995.

Hesselbein, F.; Goldsmith, M.; Beckhard, R. O líder do futuro: visões, estratégias e práticas para uma nova era. 6. ed. São Paulo: Futura, 1996.

Lemos, A. C. F. V.; Lima, S. R.; Desconci, T.; Ehlers, E. P. O planejamento estratégico como ferramenta competitiva. Anais do VII SEMEAD - Seminário em Administração da Faculdade de Economia, Administração e Contabilidade da USP. São Paulo: USP, 2004, 12 p.

Lepsch, S. L. Estratégias dos grandes e médios supermercados brasileiros na virada do século XX para o XXI: um estudo exploratório com 31 empresas do setor. 2001. 130 f. Tese de doutoramento - Faculdade de Economia, Administração e Contabilidade, Departamento de Administração, Universidade de São Paulo, São Paulo, 2001.

Revista Ibero-Americana de Estratégia RIAE, São Paulo, v. 10, n. 1, p. 170-194, jan/abr. 2011. 
A Participação do Nível Operacional no Processo de Formulação de Estratégias.

Lerner, W. Organização participativa: mais uma poderosa tecnologia na busca da competitividade. 2. ed. São Paulo: Atlas, 1996.

Maximiano, A. C. A. Além da Hierarquia: como implantar estratégias participativas para administrar a empresa enxuta. São Paulo: Atlas, 1995.

Mintzberg, H. Criando Organizações Eficazes: estruturas em cinco configurações. 2. ed. São Paulo: Atlas, 2003.

Mintzberg, H.; Quinn, J. B. O Processo da Estratégia. 3. ed. Porto Alegre: Bookman, 2001.

Mintzberg, H.; Ahlstrand, B.; Lampel, J. Safári de Estratégia: um roteiro pela selva do planejamento estratégico. Porto Alegre: Bookman, 2000.

Oliveira, D. P. R. Teoria Geral da Administração: uma abordagem prática. São Paulo: Atlas, 2008.

OLiveira, F. C. e Castelo, P. J. A administração participativa - uma experiência vivenciada no comitê da bacia hidrográfica do Curu, no estado do Ceará. Revista do Centro de Ciências Administrativas de Fortaleza, v. 11, n. especial, p. 41-51, 2005.

Ouchi, W. G. Markets, bureaucracies, and clans. Administrative Science Quarterly, n. 25, mar., 120-142, 2000.

Panegalli, J. C. Facilitando o processo de planejamento e gestão nas organizações. Revista Contemporânea de Contabilidade, ano 01, v. 01, n. 02, p. 11-40, jul./dez. 2004.

Pereira, M. J. L. B.; Fonseca, J. G. M. Faces da decisão: as mudanças de paradigmas e o poder da decisão. São Paulo: Makron Books, 1997.

Richardson, R. J. e Colaboradores. Pesquisa social: métodos e técnicas. 3. ed. São Paulo: Atlas, 2008.

Senge, P. M. A quinta disciplina: arte e prática da organização que aprende. 4. ed. São Paulo: Best Seller, 1999.

Vergara, S. C. Métodos de pesquisa em administração. 3. ed. São Paulo: Atlas, 2008.

Whiteley, R. C. A empresa totalmente voltada para o cliente: do planejamento à ação. 20. ed. Rio de Janeiro: Campus, 1992.

Wright, P.; Kroll, M. J.; Parnell, J. Administração Estratégica: conceitos. São Paulo: Atlas, 2000. 
Recebido: 10/01/2011

Aprovado: 20/03/2011

Revista Ibero-Americana de Estratégia RIAE, São Paulo, v. 10, n. 1, p. 170-194, jan/abr. 2011. 